\title{
A APLICAÇÃO DA EDUCAÇÃO AMBIENTAL NO CONTEXTO DO DISTRITO DE ITAITÚ, JACOBINA, BAHIA.
}

\section{THE EDUCATION ENVIRONMENTAL AT THE CONTEXT FROM THE DISTRICT AS OF ITAITÚ JACOBINA BAHIA}

\section{LA APLICACIÓN DE LA EDUCACIÓN AMBIENTAL EN EL CONTEXTO DEL DISTRITO DE ITAITÚ, JACOBINA BAHIA}

\author{
Fabiane Pereira da Silva Santos \\ Licenciada em Geografia pela Universidade do Estado da Bahia. \\ Especialista em Educação Ambiental e em MBA Auditoria e Perícia Ambiental pelo Instituto Brasileiro \\ de Pós-Graduação e Extensão - IBPEX. \\ E-mail: fabi_psilva@yahoo.com.br.
}

Joseane Gomes de Araújo

Licenciada em Geografia pela Universidade do Estado da Bahia.

Especialista em Educação Ambiental e em MBA Auditoria e Perícia Ambiental pelo IBPEX. Professora do município de Jacobina-BA e da Universidade do Estado da Bahia - UNEB, Campus IV.

E-mail: jgajujuba@yahoo.com.br

\section{Susana Oliveira Valois Coutinho Serrão}

Graduada em Ciências Naturais pela Universidade Federal da Bahia.

Especialista em Educação Ambiental pelo Instituto Brasileiro de Pós-Graduação e Extensão - IBPEX

Professora Estadual do Município de Miguel Calmon, Bahia.

E-mail: susanavalois@ hotmail.com

\section{Resumo}

Este artigo compreende uma análise das práticas de educação ambiental no distrito de Itaitú, situado em Jacobina, Bahia, onde as suas belezas naturais conferem ao lugar grande potencialidade para o turismo ecológico. O trabalho da Escola Municipal Cresciano Fernandes Pires, bem como as iniciativas da associação de moradores locais, foram analisadas e avaliadas por meio de uma organização chamada "Projeto Despertar" desenvolvida pela supracitada escola em parceria com a comunidade. A fim de realizar este estudo, foram aplicadas pesquisas de campo, juntamente com entrevistas e pesquisas bibliográficas. A partir deste trabalho, pode-se notar a necessidade de implantação de projetos a fim de viabilizar o turismo ecológico, assim como criar iniciativas voltadas para a preservação dos recursos naturais, resultando numa integração da comunidade local.

Palavras-Chave: educação ambiental, Distrito de Itaitú, zoneamento ecológico. 


\begin{abstract}
This article consists of an analysis of the practices in environmental education in a village nearby the town of Jacobina, Bahia, where its natural beauty gives to the place great potentiality in terms of ecological tourism. The work of the Municipal School Crescenciano Fernandes Pires, as well as the initiatives of the local residents association has been analyzed and evaluated through an organization named Projeto Despertar developed by the school in a partnership with the community. In order to accomplish this study, field surveys, alongside with interviews and bibliographical researchs were all applied. Through the results of this study, it is easily noticeable the need for projects implementation as a way to enable the development of ecological tourism, as well as the creation of initiatives aimed at preserving natural resources, as a result, integrating the local community.
\end{abstract}

Key-words: environmental education, District Itaitú, ecological zoning.

\title{
Resumen
}

Este artículo comprende una análisis de las prácticas de las enseñanza ambiental en el Distrito de Itaitú, ubicado en Jacobina, Bahia, donde sus bellezas naturales conferen al sitio gran potencialidad para el turismo ecológico. El trabajo de la Escuela Municipal Crescenciano Fernandes Pires, así como las acciones de la asociación de residentes locales, fueron analisadas y probadas por una organización llamada "Proyecto Despertar", desarrollado por la supracitada escuela junto con la comunidad. Para hacer este estudio, fueron aplicadas encuestas decampo, junto con entrevistas y pesquisas bibliográficas. Por este trabajo, puédese notar la necesidad de implantación de proyectos para tornar posible el turismo ecológico, también criar iniciativas aplicadas a la preservación de los recursos naturales, llegando a una unión de la comunidad local.

Palabras clave: enseñanza ambiental, Distrito de Itaitú, la zonificación ecológica

\section{Introdução}

No atual contexto, marcado pelas evidências e conseqüências onde o modelo de desenvolvimento econômico capitalista adotado pela sociedade mundial é agressivo à natureza e a própria qualidade de vida da espécie humana, a educação ambiental possui uma importância primordial na luta para reverter esse quadro. Encontrar caminhos para conciliar crescimento econômico e preservação dos recursos naturais precisa ser hoje o objetivo de todas as nações, no entanto sabe-se que isso implica em mudança de comportamento, em novas atitudes e posturas na relação com o meio ambiente. 
A Educação Ambiental pode ser o caminho para a construção desse novo paradigma, de uma nova forma de pensar e agir na relação homem e natureza, o que é essencial para que se tenha mais qualidade de vida.

Sabe-se que existem inúmeras práticas de Educação Ambiental e cada uma delas podem estar adequada a um contexto específico. Existem diversas maneiras de se trabalhar a Educação Ambiental, a depender da realidade e dos problemas ambientais ali existentes, sendo que toda a abordagem precisa estar permeada por uma reflexão crítica e permanente, voltada para adoção de novas posturas e de um novo modo de pensar frentes as questões ambientais. Esta prática não necessita, portanto, estar atrelada apenas a um caráter preservacionista e pragmático, pois isso pode implicar em um reducionismo.

Dessa forma, este trabalho se propõe a identificar e avaliar iniciativas de efetivação da Educação Ambiental no Distrito de Itaitú, Jacobina, Bahia-Brasil, local de grande biodiversidade e riqueza de recursos hídricos, tendo uma conseqüente potencialidade para o turismo ecológico, como também sugerir à comunidade local formas de aprimorar as iniciativas de Educação Ambiental.

Este trabalho é de relevante importância para a sociedade local, pois não existem muitas publicações sobre esta temática, abordando o caso especifico do Distrito de Itaitú. Sendo assim, este artigo pode ser útil para um futuro planejamento, voltado para a implementação de ações de preservação ambiental e gestão do turismo ecológico no referido Distrito. Cabe ressaltar ainda, que se trata de mais uma publicação na área de Educação Ambiental, visto que essa discussão encontra-se atualmente no ápice dos estudos científicos, em função da crise ambiental vivenciada atualmente.

A metodologia utilizada para a investigação desta pesquisa é baseada no referencial teórico de alguns autores, entre eles; Dias (1998), Medina (1996), Oliveira (2007), Reigota (2001), Rodrigues e Costa (2004), Santos (2001), Sato (2002) e Silva (2007). Além disso, foram feitas visitas ao local, entrevistas com moradores do Distrito, sob a liderança do presidente da Associação Comunitária e com alunos e professores da escola municipal. 


\section{Alguns pressupostos teóricos acerca da prática da Eeducação Ambiental}

O termo Educação Ambiental (EA) tem sua origem na discussão sobre a problemática da degradação dos recursos naturais do planeta, iniciada na segunda metade do século XX, vindo a ganhar ênfase com a realização de eventos importantes como a Conferência das Nações Unidas sobre "O Meio Ambiente Humano", realizada em Estocolmo, na Suécia em 1972. Essa Conferência contou com a participação de 113 países, além de Organizações Não-Governamentais (ONGs) e outros organismos internacionais e discutiu temas como: o crescimento populacional, o processo da urbanização e a tecnologia voltada para a industrialização (REIGOTA, 2001)

Outra Conferência importante foi à realizada em Tbilisi, Geórgia, no ano de 1977, com o título "Conferência Intergovernamental" sobre EA, organizada pela Organização das Nações Unidas para a Educação, a Ciência e a Cultura (UNESCO), que se constitui no ponto de partida de um programa internacional de EA, contribuindo para preservar sua natureza, definindo seus objetivos e suas características, e estratégias para as escalas nacional e internacional. Pode-se dizer que essa Conferência foi um evento importantíssimo na definição dos rumos da EA. Assim, emerge o conceito de EA, que passa a ser divulgado em vários seminários realizados pela UNESCO em alguns países do mundo (DIAS, 1998).

Várias publicações também chamaram a atenção do planeta para a problemática ambiental ao longo das três últimas décadas, dentre essas publicações pode-se destacar o Relatório Limites do Crescimento em 1972, publicado pelo Clube de Roma; o Relatório de Brandt em 1980; Estratégia Mundial de Conservação em 1980; Relatório de Brundtland no ano de 1987 e mais recentemente a Agenda 21 em 1992. Todas essas publicações e eventos contribuíram para delinear o conceito de EA, que segundo Sato (2002), hoje caminha lentamente no processo para efetivar mudanças nas atitudes e comportamentos humanos em relação ao meio ambiente.

Atualmente, a questão ambiental tornou-se algo cada vez mais latente, visto que a humanidade está aos poucos percebendo que o estilo de vida da sociedade moderna, seus padrões de produção e consumo estão causando sérios danos à natureza. Sendo assim, a EA vem sendo incorporada ao discurso dos mais diversos atores e grupos 
sociais (governantes, ONGs, mídia, empresários, cidadãos comuns e etc.) em todos os níveis, desde o local ao global.

A temática ambiental passou a fazer parte da pauta de reuniões internacionais e cada vez mais vai adentrando ao cotidiano das pessoas. Todos se apropriam desse discurso, inclusive aqueles que detêm o poder de manipular ideologicamente as classes mais desfavorecidas. Com isso, em muitos momentos, acaba sendo passada com uma característica meramente conservacionista, sendo utilizada como instrumento de marketing por algumas empresas que se dizem ambientalmente sustentáveis.

Diante de tudo isso, é importante analisar e até questionar a maneira como está sendo trabalhado o conceito de EA no âmbito da sociedade nos mais diversos contextos, bem como verificar que tipos de práticas estão sendo executadas com a etiqueta de EA, o que consiste na utilização da EA como instrumento de marketing, de forma estigmatizada.

Vários autores trazem o conceito de EA em suas obras, existindo uma vasta bibliografia sobre o tema. Reigota (2001, p.10) define, com muita precisão, a EA como sendo uma: "[...] educação política, no sentido de que ela reivindica e prepara os cidadãos para exigir justiça social, cidadania nacional e planetária, autogestão e ética nas relações sociais e com a natureza". Percebe-se que a ética e a cidadania política estão impregnadas ao conceito de EA e que não há como trabalhar com a mesma sem considerar seu aspecto político. Dessa forma, o trabalho com a EA contribui para a formação sócio-política e cidadã dos indivíduos, sendo que a conservação dos recursos naturais é uma responsabilidade de todos os cidadãos do mundo, em todas as escalas, desde a local, a internacional.

Sato (2002) traz a definição de EA instituída na Conferência de Tbilisi, que a definiu como:

[...] um processo de reconhecimento de valores e classificação de conceitos, objetivando o desenvolvimento das habilidades e modificando as atitudes em ralação ao meio, para entender e apreciar as inter-relações entre os seres humanos, suas culturas e seus meios biofísicos. A educação Ambiental também está relacionada com a prática das tomadas de decisões e a ética que conduzem para a melhoria da qualidade de vida (p. 24/25). 
Dessa forma, a EA pode ser definida como um conjunto de práticas e atividades, contextualizadas teoricamente, visando gerar uma compreensão crítica das relações existentes entre os indivíduos e o meio em que habitam, considerando as circunstâncias históricas, bem como os aspectos sociais, políticos, econômicos, culturais e biofísicos, para assim desenvolver na comunidade novas atitudes e práticas em relação à natureza. A EA tem um caráter de atividade permanente e pode estar presente na vida das pessoas.

Segundo Dias (1998), um dos aspectos acima mencionados poderá sobressai-se em detrimento do outro. Tratar a questão ambiental abordando apenas a questão ecológica seria reducionismo, conforme destaca:

Como se vê, tratar a questão ambiental abordando-se apenas um dos seus aspectos - o ecológico - seria praticar o mais ingênuo e primário reducionismo. Seria adotar o verde pelo verde, o ecologismo, e desconsiderar de forma lamentável as raízes profundas das nossas mazelas ambientais, situadas nos modelos de desenvolvimento adotados sob a tutela dos credores internacionais (p. 27).

A Lei 9.795/1999 instituiu a Política Nacional de Educação Ambiental, distinguindo a Educação Ambiental em Formal, Não-Formal e Informal. A Educação Ambiental de Ensino Formal corresponde àquela aplicada no âmbito das escolas, podendo ser abordado como um tema transversal. A Educação Ambiental Não-Formal é aquela de caráter não-oficial praticada por educadores, instituições e várias atividades, sendo obrigação do poder público incentivá-la. Quanto a Educação Ambiental Informal é aquela praticada pela mídia, por meio de matérias que induzem mudanças de atitudes e comportamento, bem como uma reflexão critica (RODRIGUES e COSTA, 2004).

Medina (1996) aborda essa questão da Educação Ambiental formal e não-formal ao afirmar que:

[...] a educação ambiental pode fornecer algumas respostas para os processos de adequação e transformação da educação formal e não-formal nos próximos anos, sempre que ela se proponha a atingir a superação dos posicionamentos ingênuos, que em grande parte tem sido característica no que se refere a analise dos problemas sócio-ambientais e, mais especificamente aos problemas pedagógicos que ela traz em seu bojo (p. 159). 
Sendo assim, todas as formas de aplicação da EA, seja de ensino formal, nãoformal ou informal, são extremamente importantes, na medida em que atingem diferentes espaços (escola e espaços sociais diversos), contribuindo para a construção de concepções voltadas para a preservação do meio ambiente em vários contextos sociais, visando mudanças de atitudes e comportamento.

Reigota (2001) aponta que na Carta de Belgrado, a EA possui seis objetivos principais: a) Conscientização: focada na consciência dos problemas ambientais; b) Conhecimento: relacionada à compreensão do meio ambiente, os seus problemas e o papel do ser humano frente a essas questões; c) Comportamento: voltado para adoção de novas posturas e valores em relação ao meio ambiente; d) Competência: referente à qualificação necessária à solução dos problemas ambientais; e) Capacidade de avaliação: visa levar os indivíduos a buscar avaliar programas relacionados ao meio ambiente; f) Participação: levar os indivíduos e grupos a perceber a sua responsabilidade frente aos problemas ambientais.

Esses objetivos são fundamentais para a concretização da educação ambiental em um determinado meio e estão voltados para efetivação de práticas de conservação dos recursos naturais.

Dentre os avanços da EA, podem-se destacar melhorias no campo teórico, hoje se tem várias publicações na área ambiental e um rico material bibliográfico sobre o assunto. Outro avanço importante é a multiplicação de ministérios e órgãos responsáveis pela pasta do meio ambiente em vários países, além da criação de legislações regulamentando a questão.

Em face de todas as discussões, crescem aos poucos as iniciativas de promoção da EA em escolas, ONGs, grupos sociais diversos, como também aumenta o número de cursos de graduação e pós-graduação na área de educação ambiental.

Verifica-se que os maiores avanços na área ambiental acabam resumindo-se ao campo teórico e muito pouco foi feito para sanar os problemas ambientais globais. As iniciativas de EA a nível local, muitas vezes têm um caráter meramente conservacionista, deixando de lado os aspectos políticos, culturais e socioeconômicos que fazem parte da EA.

É importante questionar o tipo de abordagem que vem permeando as práticas de EA. Em muitas situações percebe-se que as práticas intituladas de "fazer educação 
ambiental", seja em sala de aula ou em qualquer outro espaço educativo, estão impregnadas de uma visão conservacionista, voltada para a preservação da natureza ingenuamente idealizada, deixando de lado o caráter político e social presente na EA.

O objetivo da EA vai muito além de simplesmente preservar os recursos naturais, mas caracteriza-se por estar voltada para uma mudança de paradigma na atual organização social, ou seja, a sociedade precisa encontrar novas formas de se organizar e descobrir caminhos para explorar de maneira mais sustentável a natureza. Isso implica na adoção de novos hábitos na relação homem x natureza.

\section{Caracterização da área de estudo}

O distrito de Itaitú está localizado a cerca de $24 \mathrm{~km}$ da sede do município de Jacobina. A palavra Itaitú em indígena quer dizer pedra grande, sendo também denominado Riachão de Jacobina (SANTOS, 2001).

No decorrer dessa pesquisa não foi possível ter acesso a dados históricos do Distrito, mas em entrevistas junto aos moradores antigos, percebe-se que a origem do Distrito está ligada ao processo de expansão para o interior, com a catequização dos índios que habitavam a região. Algumas evidências são encontradas na presença da igreja católica erguida em estilo barroco, com técnicas de construção rudimentares, que segundo os moradores foi erguida pelos índios.

\section{Aspectos Naturais}

O Distrito de Itaitú possui grande potencialidade para o turismo ecológico, em função de suas características naturais, como a presença de várias quedas d'águas, vegetação exuberante e relevo acidentado.

A paisagem natural de Itaitú difere da tipologia das paisagens do Piemonte da Chapada Diamantina, graças a sua topografia, solos férteis e temperatura amena, devido à proximidade das serras.

A vegetação predominante é remanescente de Mata Atlântica, com floresta estacional e semidecidual, perdendo as folhas em parte do ano. Dentre as espécies vegetais encontradas pode-se destacar a bromélia, o ipê, o cedro e pau d'arco. 
Aspectos Sócioeconômicos

O distrito de Itaitú é habitado por cerca de 800 pessoas, segundo informações da Associação de Moradores do Distrito de Itaitú. As principais atividades econômicas são: a agricultura, com plantio de feijão, milho e mandioca, e também o turismo. A atividade comercial está se desenvolvendo aos poucos, a partir do aumento do movimento de turistas e do crescimento da demanda dos moradores. Dentre as atividades comerciais lá encontradas, tem-se: mercadinhos, padarias, bares, pousadas e restaurantes.

Dessa forma, a população de Itaitú dispõe de uma facilidade para adquirir recursos que satisfaçam suas necessidades básicas, no entanto faltam iniciativas e projetos para melhor estruturar a economia do local, na área turística e também agrícola. Itaitú possui uma grande potencialidade para o desenvolvimento do Ecoturismo se destacando por uma série de atrativos relevantes e pertinentes ao desenvolvimento turístico, mas ainda precisa de ações viabilizadas pelo poder público municipal por meio de fontes de recursos para o desenvolvimento sustentável do turismo, com uma infraestrutura receptiva adequada a partir de um bom planejamento, em que a comunidade faça parte de todo processo de revitalização do local.

Em entrevista com o presidente da Associação de Moradores, o senhor Níveo Antônio Oliveira da Silva, foi possível constatar que a assistência fornecida pela prefeitura municipal aos moradores da localidade ainda deixa muito a desejar, pois falta um posto de saúde, posto policial funcionando regulamente, ambulâncias, etc. Segundo os moradores, necessita-se de uma parceria entre prefeitura e a comunidade local, representada pela Associação, no sentido de organizar a atividade de Ecoturismo, com a capacitação de guias e fiscais, bem como a construção de um posto de informações turísticas.

\section{A prática da Educação Ambiental no distrito de Itaitu, Jacobina, Bahia.}

O Distrito de Itaitú, como já foi ressaltado anteriormente, apresenta um potencial natural e turístico invejável. Suas serras, belas cachoeiras e nascentes proporcionam aos visitantes e aos moradores da localidade um cenário agradável para o Ecoturismo, no 
entanto, foi possível constatar por meio de entrevistas e visitas in locu, que a atividade de turismo ecológico ainda é extremamente desorganizada e que as iniciativas de EA resumem-se a projetos desenvolvidos pela escola, a exemplo do Projeto Despertar, como o envolvimento dos alunos e da comunidade.

A escola municipal Crescenciano Fernandes Pires, a única existente no Distrito, somente em meados do ano 2007, começou a trabalhar com a EA a partir da implantação desse projeto, em que todos os segmentos de ensino estão envolvidos, a partir do estudo de temas pré-estabelecidos, como por exemplo, lixo, solo, água, biodiversidade, etc. Em entrevista, alguns professores nos relataram que a aceitação e participação dos alunos nas atividades do projeto ainda é limitada, pois há uma indisposição dos alunos nas reflexões acerca dos temas. Apesar disso, pequenas mudanças são visíveis nas ações e no discurso dos alunos em relação ao meio ambiente.

É importante ressaltar ainda, que em entrevista com os professores da escola municipal do Distrito, nos foi relatado pelos mesmos que a unidade não dispõe de recursos e equipamentos necessários a realização de um bom trabalho de EA, pois faltam computadores e materiais didáticos.

Além disso, a Associação de moradores local possui uma tímida luta para conter a degradação ambiental, por meio de protestos e reivindicações, como a ação movida por meio do Ministério Público de Jacobina contra empresas que vinham extraindo madeira ilegal na região. Quanto à participação dos moradores nas reuniões e atividades da Associação nota-se que ainda é muito reduzida, pois segundo o próprio presidente da associação apenas vinte e duas pessoas participam ativamente das reuniões. Algumas pessoas mais idosas alegam que já não têm mais idade para reuniões e discussões. Vale ressaltar ainda, que alguns moradores resistem em adotar novas posturas na relação com o meio ambiente, por não visualizarem alternativas de sobrevivência, já que muitos extraem da natureza, por meio da caça o seu sustento.

Foi possível constatar que as iniciativas de EA existentes no Distrito de Itaitú, sejam elas promovidas pela escola e/ou pela associação, apresentam um caráter conservacionista do meio ambiente (caminhadas ecológicas, mutirões para coletar lixo das cachoeiras, etc.), que segundo Silva (2007) apresenta ênfase na proteção ao longo do curso d'água, detendo-se aos problemas ambientais mais aparentes e desprezando as causas mais profundas, geralmente não abordando questões sociais e políticas. As 
atividades são voltadas para soluções emergenciais, não possuindo um caráter permanente e que esteja voltado para uma mudança de conduta em relação ao meio ambiente.

Essas iniciativas são importantes, mas é importante lembrar que a EA precisa estar focada na construção de uma nova visão por parte dos indivíduos da importância do uso racional dos recursos naturais, implicando em novos padrões de vida e comportamento, de forma permanente.

Silva (2007) coloca que no contexto da sala de aula, a EA pode ser trabalhada de forma crítica e reflexiva, levando os alunos a compreenderem o seu papel na construção de sociedades mais justas, exercendo suas atribuições na busca de melhores condições sócio-ambientais. É importante destacar que a concepção crítica da EA possibilita o desenvolvimento de uma consciência baseada na visão holística do meio ambiente, isto é, levando em consideração questões atuais e futuras, as causas e conseqüências dos problemas ambientais, relações ideológicas, tecnológicas e econômicas, além das diferentes escalas espaciais e de poder, desde o local ao global. Nesse sentido, o professor necessita atuar como mediador no processo de construção de saberes, viabilizando ações, pesquisas e reflexões, que gerem novas posturas diante os problemas ambientais.

Sato (2002) coloca que conhecer as representações dos indivíduos e grupos sociais sobre o meio ambiente, é extremamente importante para orientar as atividades de EA. Percebe-se que as concepções de meio ambiente dos moradores entrevistados estão de fato compreendendo o meio ambiente como um local de relações entre a natureza e a sociedade, o que pode se considerar um aspecto positivo a qualquer iniciativa de EA que venha a ser implantada no Distrito. Pode-se atribuir essa visão ao fato de os moradores desta localidade viverem em permanente contato com a natureza e retirarem dela o seu próprio sustento, estando este núcleo de povoamento situado em um meio de grande biodiversidade.

As entrevistas com os moradores apontam que o turismo poderia de fato ser algo benéfico à comunidade, no entanto, falta infra-estrutura, organização e apoio logístico da prefeitura, a fim de desenvolver habilidades para as pessoas atuarem nessa atividade. Nota-se que existe um reconhecimento por parte dos moradores da necessidade de 
preservar a natureza local, como também boa vontade dos mesmos para contribuir para isto.

A área do distrito não possui ainda nenhum zoneamento ecológico, que possibilite um maior conhecimento das potencialidades locais e características físicas e biológicas, o que dificulta a fiscalização e não cria embargos à ação de empresas que queiram explorar os recursos naturais, a exemplo da Jacobina Mineração e Comércio S/A. ${ }^{1}$

Em entrevista com o coordenador de meio ambiente do município, o senhor Ivan Aquino, nos foi relatado que a prefeitura municipal, por intermédio da Coordenação de Meio Ambiente, vem trabalhando na implantação de um zoneamento ecológico da área de Itaitu, visando transformá-la em monumento natural, que tem como objetivo básico preservar sítios naturais raros, singulares ou de grande beleza cênica, podendo ser constituído por áreas privadas, desde que os objetivos de utilização da terra e dos recursos naturais dos proprietários sejam compatíveis com a proposta do orgão responsável pela administração da unidade. A visitação é regulada por um Plano de Manejo da unidade, visando assegurar a conservação da diversidade biológica, a partir de normas e critérios previamente estabelecidos.

Essa iniciativa de zoneamento ecológico seria adequada para preservar os recursos naturais do distrito e organizar o turismo ecológico, porém a implantação do mesmo implicaria em conflitos com os proprietários de terra do local, que poderiam recusar-se a abrir mão de sua privacidade ou mesmo de suas terras. Dessa forma, seria necessário também um trabalho de conscientização desses proprietários de terra da importância da preservação dos recursos naturais.

A organização da questão do turismo ecológico em Itaitu precisa estar atraleda a implantação de um processo permanente de EA, a fim de utilizar economicamente as potencialidades naturais de forma sustentável, beneficiando os moradores do local e contribuindo para a preservação da biodiversidade. Trata-se da criação de um ambiente de lazer e recreação, no qual a EA possa estar presente em todas as atividades realizadas com os visitantes. No entanto, sabe-se que isso poderia ser viável com a implantação de um zoneamento ecológico na área, possibilitando a implantação de um Plano de Manejo

\footnotetext{
${ }^{1}$ Empresa que já atua na extração de ouro na sede do município, liberada pelo grupo canadense Yamana Gold, que conseguiu recentemente uma licença de órgãos estaduais para realizar pesquisas geológicas visando uma futura extração aurífera, o que pode vir a prejudicar os mananciais hídricos da região.
} 
da Unidade, para orientar a fiscalização e promover um planejamento estrutural das atividades na localidade.

\section{Conclusões}

Considerando a Educação Ambiental como sendo um processo complexo, necessita ser composta nos diferentes níveis de análise (local, regional, nacional e global), envolvendo os múltiplos atores sociais que atuam no campo da representação social, política e econômica, a fim de definir estratégias factíveis de acordo com a lógica da Educação Ambiental.

Sendo assim, percebe-se que os desafios relacionados à prática da EA são diversos e que é um processo em que todos os indivíduos precisam estar envolvidos para a construção de novos valores sociais, conhecimentos, habilidades e competências que visem à conservação do meio ambiente para uma melhor qualidade de vida, superando os problemas e desafios relacionados à EA para a construção de pilares democráticos e sustentáveis.

Nessa perspectiva, sugerem-se ações a serem promovidas para a preservação do ambiente privilegiado do distrito de Itaitú, podendo ser algumas dessas abaixo citadas:

- Organizar as atividades de turismo ecológico por meio do envolvimento da escola e comunidade;

- Construir uma infra-estrutura adequada ao turismo ecológico, como hotéis, restaurantes, capacitação de guias, postos de informações, além de promover o saneamento básico adequado, com esgotamento sanitário e a criação de um local apropriado para disposição regular de resíduos sólidos e líquidos.

- Desenvolver um trabalho de Educação Ambiental com recursos e equipamentos necessários;

- Ampliar o trabalho junto à associação de moradores no sentido de buscar alternativas com maior liberdade para os problemas apresentados na comunidade;

- Ampliar a participação dos moradores nos trabalhos da Associação local; 
- Apresentar novas alternativas de reprodução socieconomica para a comunidade que se utilizam da natureza com práticas predatórias para se manter;

- Promover atividades de caráter permanente voltadas para a adoção de novas posturas e atitudes na relação com o meio ambiente;

- Trabalhar a Educação Ambiental de forma crítica e reflexiva de forma que os envolvidos compreendam o seu papel na construção de sociedades menos injustas;

- Implantar um zoneamento ecológico na área do distrito, transformando-o em patrimônio natural;

- Criar um ambiente de lazer e recreação em que a Educação Ambiental esteja presente em todas as atividades com os turistas.

É importante frisar que, há muito que avançar nos estudos referentes a Educação Ambiental no Distrito de Itaitú, como também no município de Jacobina, a fim de melhor orientar ações e iniciativas de implantação de projetos de conservação dos recursos naturais do município e do turismo ecológico. Assim, sugere-se a realização de pesquisas voltadas para catalogar espécies animais e vegetais existentes em Itaitú, bem como a construção de uma análise mais profunda da atual situação dos recursos hídricos locais, a fim de subsidiar a escolha de um método de zoneamento ecológico adequado a realidade do lugar.

\section{Referências}

DIAS, G. F. Educação Ambiental: princípios e práticas. 5. Ed. São Paulo: Global, 1998.

MEDINA, N. M. Educação Ambiental para o século XXI. In: Encontro dos Centros de Educação Ambiental. Série Meio Ambiente em debate. IBAMA: Brasília, 1996. Disponível

em: http://www.ufpa.br/numa/especializ/cursos_especializacao/2007/Educacao\%20Ambient al/NANA-EA-Seculo-XXI.pdf. Acesso em: 19/set./2007.

OLIVEIRA, L. F.C. de. Uma análise das intervenções em Educação Ambiental numa Instituição de alunos com necessidades educativas especiais. 2007, $120 \mathrm{f}$. Dissertação (Mestrado em Educação) - Faculdade de Educação da Universidade de São Paulo, São Paulo. 
REIGOTA, M. O que é Educação Ambiental. São Paulo: Brasiliense, 2001.

RODRIGUES, M. G. S.; COSTA, R. de S. O. da. A Integração da Educação Ambiental Formal e Não-Formal: Participação e Cidadania. In: $1^{\circ}$ Congresso Acadêmico sobre Meio Ambiente e Desenvolvimento do Rio de Janeiro (Cadma-RJ), 2004. Disponível em http://www.ebape.fgv.br/radma/doc/SMA/SMA-040.pdf. Acesso em: 07/set./2007.

SANTOS, A. S. dos. Turismo e Ecoturismo: o caso de Jacobina - Bahia. 2001. 37 fls. Monografia (Especialização em Turismo e Desenvolvimento Sustentável) - Curso de Pós Graduação Latu Sensu em Turismo e Desenvolvimento Sustentável, Universidade do Estado da Bahia, Campus IV, Jacobina, Bahia.

SATO, M. Educação Ambiental. São Carlos: Rima, 2002.

SILVA, R. F. L. O Meio Ambiente por trás da tela: o estudo das concepções de Educação Ambiental dos filmes da TV escola. 2007, 254f. Tese (Doutorado - Programa de Pós Graduação em Ciência e Matemática) - Faculdade de Educação da Universidade de São Paulo, São Paulo.

Recebido para publicação em setembro de 2010 Aprovado para publicação em novembro de 2010 